\title{
Oxygen Free Radicals in Ischemic Acute Renal Failure in the Rat
}

\author{
Mark S. Paller, John R. Hoidal, and Thomas F. Ferris \\ University of Minnesota, Department of Medicine, \\ Minneapolis, Minnesota 55455
}

bstract. During renal ischemia, ATP is degraded to hypoxanthine. When xanthine oxidase converts hypoxanthine to xanthine in the presence of molecular oxygen, superoxide radical $\left(\mathrm{O}_{2}^{-}\right)$is generated. We studied the role of $\mathrm{O}_{2}^{-}$and its reduction product $\mathrm{OH} \cdot$ in mediating renal injury after ischemia. Male Sprague-Dawley rats underwent right nephrectomy followed by $60 \mathrm{~min}$ of occlusion of the left renal artery. The $\mathrm{O}_{2}^{-}$scavenger superoxide dismutase (SOD) was given $8 \mathrm{~min}$ before clamping and before release of the renal artery clamp. Control rats received 5\% dextrose instead. Plasma creatinine was lower in SOD treated rats: 1.5, 1.0, and 0.8 $\mathrm{mg} / \mathrm{dl}$ vs. $2.5,2.5$, and $2.1 \mathrm{mg} / \mathrm{dl}$ at 24,48 , and $72 \mathrm{~h}$ postischemia. $24 \mathrm{~h}$ after ischemia inulin clearance was higher in SOD treated rats than in controls (399 vs. 185 $\mu \mathrm{l} / \mathrm{min})$. Renal blood flow, measured after ischemia plus 15 min of reflow, was also greater in SOD treated than in control rats. Furthermore, tubular injury, judged histologically in perfusion fixed spedimens, was less in SOD treated rats. Rats given SOD inactivated by prior incubation with diethyldithiocarbamate had plasma creatinine values no different from those of control rats. The $\mathrm{OH}$ - scavenger dimethylthiourea (DMTU) was given before renal artery occlusion. DMTU treated rats had lower plasma creatinine than did controls: $1.7,1.7$, and $1.3 \mathrm{mg} / \mathrm{dl}$ vs. $3.2,2.2$, and $2.4 \mathrm{mg} / \mathrm{dl}$ at 24,48 , and 72 $h$ postischemia. Neither SOD nor DMTU caused an increase in renal blood flow, urine flow rate, or solute excretion in normal rats. The xanthine oxidase inhibitor allopurinol was given before ischemia to prevent the generation of oxygen free radicals. Plasma creatinine

This work was presented in abstract form to the Central Society for Clinical Research, Chicago, 1983 and to the American Society of Nephrology, 16th annual meeting, Washington DC, 1983.

Received for publication 13 December 1983 and in revised form 6 June 1984.

J. Clin. Invest.

(c) The American Society for Clinical Investigation, Inc.

0021-9738/84/10/1156/09 $\$ 1.00$

Volume 74, October 1984, 1156-1164 was lower in allopurinol treated rats: $2.7,2.2$, and 1.4 $\mathrm{mg} / \mathrm{dl}$ vs. $3.6,3.5$, and $2.3 \mathrm{mg} / \mathrm{dl}$ at 24,48 , and $72 \mathrm{~h}$ postischemia. Catalase treatment did not protect against renal ischemia, perhaps because its large size limits glomerular filtration and access to the tubular lumen. Superoxide-mediated lipid peroxidation was studied after renal ischemia. $60 \mathrm{~min}$ of ischemia did not increase the renal content of the lipid peroxide malondialdehyde, whereas ischemia plus 15 min reflow resulted in a large increase in kidney lipid peroxides. Treatment with SOD before renal ischemia prevented the reflow-induced increase in lipid peroxidation in renal cortical mitochondria but not in crude cortical homogenates. In summary, the oxygen free radical scavengers SOD and DMTU, and allopurinol, which inhibits free radical generation, protected renal function after ischemia. Reperfusion after ischemia resulted in lipid peroxidation; SOD decreased lipid peroxidation in cortical mitochondria after renal ischemia and reflow. We conclude that restoration of oxygen supply to ischemic kidney results in the production of oxygen free radicals, which causes renal injury by lipid peroxidation.

\section{Introduction}

The most common cause of acute renal failure is renal ischemia, which causes renal functional impairment through a combination of renal vasoconstriction, renal tubular obstruction, tubular back leakage of glomerular filtrate, and decreased glomerular permeability. However, the nature of the cellular insult that produces these changes is unknown. A decrease in high energy phosphate supply, increase in free intracellular calcium concentration, loss of cellular synthetic function, activation of membrane degradative processes, and generation of endogenous membrane toxins are some of the factors that have been postulated to mediate cellular injury during ischemia (1). An understanding of the nature of the cellular insult in acute renal failure would have broad application since ischemia injures all organs. Also, an understanding of the mechanisms of cell injury in acute renal failure might open new therapeutic avenues not now available.

Renal ischemia results in a rapid decrease in tissue ATP (2) and a rise in the ATP degradation products adenosine, 
inosine, and hypoxanthine $(3,4)$. The loss of adenosine from cells by degradation during ischemia is believed to result in the depletion of adenine nucleotides, which persists for some time even after reestablishment of blood flow. Another effect of the accumulation of hypoxanthine during renal ischemia might be the generation of highly reactive oxygen free radicals, since the enzymatic conversion of hypoxanthine to xanthine by xanthine oxidase generates superoxide radical $\left(\mathrm{O}_{2}^{-}\right)$as a reduction product of molecular oxygen (5). Superoxide radical and its reduction products, hydrogen peroxide $\left(\mathrm{H}_{2} \mathrm{O}_{2}\right)$ and hydroxyl radical $(\mathrm{OH} \bullet)$, can produce cellular injury through lipid peroxidation of mitochondrial, lysosomal, and plasma membranes, which can alter both membrane structure and function $(6,7)$. A role for participation of oxygen free radicals in injury after hypoxia insult has been found in the brain, heart, and intestine of experimental animals (8-11), but studies in the kidney are lacking.

Normally, tissues contain enough endogenous scavengers to protect against oxygen free radical damage. Superoxide dismutase (SOD), ${ }^{1}$ one such scavenger, causes rapid removal of $\mathrm{O}_{2}^{-}$; catalase and glutathione peroxidase inactivate $\mathrm{H}_{2} \mathrm{O}_{2}$; and a variety of $\mathrm{OH}^{*}$ scavengers exist, including tryptophan, histidine, ascorbate, and alpha-tocopherol (12). During ischemia, however, supplies of these endogenous scavengers may be depleted, permitting cellular injury by oxygen free radicals, especially when tissue perfusion and oxygen delivery are restored. In support of this hypothesis are the findings after brain ischemia of a time dependent decrease in ascorbic acid levels (8) and after cardiac hypoxia of decreased SOD and glutathione peroxidase activity (10).

The purpose of the present study was to determine whether oxygen free radicals play a role in mediating injury after renal ischemia. The ability of oxygen free radical scavengers to protect renal function in the rat after renal ischemia was determined, and the effect of ischemia and reflow on lipid peroxidation in the kidney was examined.

\section{Methods}

Renal function after ischemia. Male Sprague-Dawley rats (HarlanSprague-Dawley, Madison, WI) weighing 280 to $350 \mathrm{~g}$ were used. Al animals had free access to standard rat chow and water. After sodium pentobarbital anesthesia $(60 \mathrm{mg} / \mathrm{kg}$, i.p.), a femoral vein catheter (PE50) was placed for the administration of drugs. Bilateral flank incisions were made and the right kidney was removed. The left renal pedicle was then dissected to expose the left renal artery, and heparin (10 IU per $100 \mathrm{~g}$, i.v.) was administered. A nontraumatic vascular clamp was placed across the renal artery for $60 \mathrm{~min}$. Afterwards, the incisions were closed and the animal was allowed to recover. Blood was collected daily from the end of a cut tail for determination of plasma creatinine

1. Abbreviations used in this paper: DMTU, dimethylthiourea; MDA, malondialdehyde; RBF, renal blood flow; SOD, superoxide dismutase; $\mathrm{U}_{\mathrm{Cr}}$ urinary creatinine; $\mathrm{U}_{\mathrm{Na}}$, urinary sodium; $\mathrm{U} / \mathrm{P}$, urine-to-plasma; $\mathrm{V}$, urinary volume.
(Creatinine Analyzer 2; Beckman Instruments Inc., Fullerton, CA). This model was then used to study the effect of various scavengers of oxygen free radicals. The dosages of scavengers were based on other animal studies in the literature and the limits of drug solubility but are largely empiric. The following groups of rats were studied.

Superoxide dismutase. The $\mathrm{O}_{2}^{-}$scavenger SOD (from bovine blood; Sigma Chemical Co., St. Louis, MO) was administered to six rats before renal artery occlusion. The drug was given intravenously, $8 \mathrm{mg} / \mathrm{kg}, 8 \mathrm{~min}$ before renal artery clamping and $8 \mathrm{~min}$ before the release of the vascular clamp. Control animals $(n=10)$ received the vehicle, $0.5 \mathrm{ml} 5 \%$ dextrose, before clamping and before release of the clamp. A third group of eight rats received the same dose of SOD, which had been inactivated by incubation with $0.01 \mathrm{M}$ diethyldithiocarbamate (Sigma Chemical Co.) at $56^{\circ} \mathrm{C}$ for $1.5 \mathrm{~h}$ followed by dialysis against distilled water for $20 \mathrm{~h}$ at $4^{\circ} \mathrm{C}$ (13). The efficacy of the inactivation procedure was demonstrated by the inability of the treated SOD to inhibit superoxide-mediated reduction of ferricytochrome c by xanthine plus xanthine oxidase in vitro when assayed by the method of Salin and McCord (14). Additional groups of control ( $n$ $=11)$ and SOD treated rats $(n=11)$ underwent determination of inulin clearance $24 \mathrm{~h}$ after renal ischemia. These rats were anesthesized with pentobarbital, catheters were placed in the femoral artery and vein and in the bladder, and an infusion of inulin (10\%) was begun at $0.06 \mathrm{ml} / \mathrm{min}$ for $15 \mathrm{~min}$, followed by $0.02 \mathrm{ml} / \mathrm{min}$ for the duration of the study. After a 60-min equilibration period during which mean arterial blood pressure was monitored, two 30-min urine collections were made. Blood for plasma inulin determination was obtained at the midpoint of each urine collection. The concentration of inulin in urine and blood was determined by the anthrone method, and inulin clearance was calculated by the standard formula. In other rats the effect of ischemia on renal blood flow (RBF) was determined. Rats were given SOD $(n=5)$ or $5 \%$ dextrose $(n=6)$, as above, and after $60 \mathrm{~min}$ of ischemia plus $15 \mathrm{~min}$ of reflow, RBF was measured by the radiolabeled microsphere method. Animals were prepared as above except that a PE-50 catheter was placed via the right carotid artery into the left ventricle for microsphere injection. Plastic microspheres (3M, St. Paul, MN), $15 \mu \mathrm{m}$ diam labeled with ${ }^{85} \mathrm{Sr}$ were used as previously described (15).

Dimethylthiourea (DMTU). The hydroxyl radical scavenger DMTU (Bodman Chemicals, Media, PA) (16) was administered to nine rats in a dose of $500 \mathrm{mg} / \mathrm{kg}$ i.v. $8 \mathrm{~min}$ before renal artery occlusion. Six control rats received the vehicle, $1.0 \mathrm{ml} 5 \%$ dextrose. These rats, after removal of the renal artery clamp, were housed individually in metabolism cages so that 24-h urine collections could be made. Urinary volume $(\mathrm{V})$, creatinine $\left(\mathrm{U}_{\mathrm{Cr}}\right)$, and sodium $\left(\mathrm{U}_{\mathrm{Na}}\right)$ were measured, and the urine-to-plasma $(U / P)$ creatinine ratio and $U_{\mathrm{Na}} / U / P$ creatinine were calculated.

To determine whether SOD or DMTU caused an increase in either renal blood flow, urine flow rate, or solute excretion, additional studies were performed. Normal rats, anesthetized with pentobarbitol, underwent right nephrectomy and then renal blood flow was determined. Rats were given vehicle $(n=8)$, SOD $8 \mathrm{mg} / \mathrm{kg}(n=6)$, or DMTU $500 \mathrm{mg} / \mathrm{kg}(n=6)$ as a single intravenous dose with a total volume of $1.0 \mathrm{ml}$. Other normal rats were anesthetized with pentobarbitol, the right kidney was removed, and polyethylene catheters (PE-50) were placed in the right femoral artery and vein for blood pressure monitoring and drug administration, and in the left ureter (PE-10) for urine collection. Animals were given $1.0 \mathrm{ml}$ of $5 \%$ dextrose intravenously and three 20-min urine collections were made. The rats then received either SOD $(n=5)$ or DMTU $(n=5)$ in the above doses, and three 
additional 20-min collections were made. Measurements of $\mathrm{V}, \mathrm{U}_{\mathrm{N}}$ (model FLM 3 flame photometer; Radiometer Co., Copenhagen), and urinary osmolality (model 5100B vapor pressure osmometer; Wescor, Inc., Logan, UT) were performed.

Catalase. The hydrogen peroxide scavenger catalase (Sigma Chemical Co.) was given intravenously to six rats in a dose of $8 \mathrm{mg} /$ $\mathrm{kg}, 8 \mathrm{~min}$ before renal artery clamping and $8 \mathrm{~min}$ before release of the clamp. Six control rats received dextrose instead.

Allopurinol. The xanthine oxidase inhibitor allopurinol (Sigma Chemical Co.) was given to eight rats in a dose of $40 \mathrm{mg} / \mathrm{kg}$ i.v. $8 \mathrm{~min}$ before renal artery occlusion. Nine control rats received an equal volume of the vehicle, $1.0 \mathrm{ml} 0.1 \mathrm{~N} \mathrm{NaOH}$.

Morphologic studies. Kidneys from control or SOD treated rats were examined by light microscopy. Animals given vehicle or SOD before ischemia were studied after $24 \mathrm{~h}$ of reflow (control, $n=5$; SOD, $n=6$ ). Kidneys were fixed by perfusion at mean arterial pressure with $1.25 \%$ glutaraldehyde in $0.1 \mathrm{M}$ sodium cacadoylate buffer $(\mathrm{pH}$ 7.4, osmolality 300 ) followed by immersion in this fixative for $3 \mathrm{~h}$. Sections were embedded in paraffin and stained with hematoxylin and eosin. Slides were reviewed blindly and scored with a semiquantitative scale evaluating changes found in acute renal failure $(17,18)$. Specifically, for each kidney 100 cortical tubules from at least 10 different areas were scored, and care was taken to avoid repeated scoring of different convolutions of the same tubule. Higher scores represented more severe damage (maximum score per tubule was 10), with points given for the presence and extent of tubular epithelial cell flattening (1 point), brush border loss (1 point), cell membrane bleb formation (1 or 2 points), interstitial edema (1 point), cytoplasmic vacuolization (1 point), cell necrosis ( 1 or 2 points), and tubular lumen obstruction (1 or 2 points).

Lipid peroxidation by oxygen free radicals. The effect of both ischemia and reflow on lipid peroxidation was evaluated in another group of animals. Rats that had received either vehicle or SOD underwent $60 \mathrm{~min}$ of renal artery occlusion and $15 \mathrm{~min}$ of reflow, and lipid peroxidation of kidney membranes was determined. The lipid peroxide malondialdehyde (MDA) was measured as a marker for membrane lipid peroxidation by the method of Ohkawa et al. (19). Kidneys were rapidly removed and placed in iced phosphate buffered saline. Whole kidneys were then transferred to tubes containing $10 \mathrm{ml}$ (final volume) $0.25 \mathrm{M}$ sucrose plus $0.003 \mathrm{M}$ EDTA, and homogenized with a Teflon-glass homogenizer. In other studies, sections of renal cortex were suspended in a total volume of $3 \mathrm{ml}$. In the studies of mitochondrial membrane peroxidation, mitochondrial suspensions were obtained by centrifugation of renal cortical homogenates at $600 \mathrm{~g}$ for $10 \mathrm{~min}$ followed by centrifugation of the supernate at $4,800 \mathrm{~g}$ for 15 min. The mitochondria-enriched pellet was resuspended in $0.25 \mathrm{M}$ sucrose and assayed as for whole kidney or cortical homogenates. 200 $\mu l$ of homogenate was added to $0.2 \mathrm{ml} 8.1 \%$ sodium dodecyl sulfate, $1.5 \mathrm{ml} 20 \%$ acetic acid, $1.5 \mathrm{ml}$ thiobarbituric acid, and $6.6 \mathrm{ml}$ water. This solution was heated to $95^{\circ} \mathrm{C}$ for $60 \mathrm{~min}$. After the addition of $1.0 \mathrm{ml}$ water and $5.0 \mathrm{ml}$ of an $n$-butanol/pyridine mixture $(15: 1 \mathrm{vol} /$ vol) the mixture was vigorously shaken and centrifuged at $2,000 \mathrm{~g}$ for $15 \mathrm{~min}$. The absorbance of the upper organic layer at $532 \mathrm{~nm}$ was determined in a spectrophotometer. Absorbance of tissue samples was compared with results obtained using malonaldehyde tetraethylacetal standards (Sigma Chemical Co.). Whole kidney values were corrected for total weight of the discarded kidney (as a close approximation of the preischemic weight of the kidney studied), and cortical and mitochondrial values were corrected for protein content. All assays were performed immediately after the removal of kidneys, and deter- minations of MDA were performed in duplicate. The intraassay coefficient of variation was $4.2 \%$. Each time the assay was performed a freshly harvested nonischemic kidney was also assayed to determine the baseline level of MDA in normal renal tissue under the assay conditions.

Statistical analysis. All data are reported as the mean \pm standard error. Statistical comparisons between two groups was made by the unpaired $t$ test, except as noted. Analysis of variance was used to analyze multigroup studies, such as the effect of vehicle, SOD, and inactive SOD on renal function after ischemia. Intergroup comparisons were then made with Duncan's multiple range test. The Wilcoxon rank sum test was used to analyze the MDA data that appeared to be nonparametric in distribution. The paired $t$ test was used to analyze the effects of SOD or DMTU on solute excretion.

\section{Results}

Renal function after renal ischemia. Occlusion of the renal artery for $60 \mathrm{~min}$ in rats with contralateral nephrectomy resulted in a marked decrease in renal function which recovered within 1 wk. As shown in Fig. 1, peak plasma creatinine, $2.5 \pm 0.3 \mathrm{mg} / \mathrm{dl}$ was observed on day 1 after ischemia, with little change in plasma creatinine during the next $24 \mathrm{~h}$. Thereafter, renal function improved so that plasma creatinine was similar to that of control animals by day 7 .

Effect of oxygen free radical scavengers on renal function after ischemia. Administration of SOD before ischemia resulted in a significant attenuation of functional impairment. As seen in Fig. 1, plasma creatinine rose to only $1.5 \pm 0.2 \mathrm{mg} /$ $\mathrm{dl}$ on day $1(P<0.05)$ and remained lower than in control animals during the recovery phase. Inactivated SOD provided no protection against the functional impairment of ischemia (Fig. 1); plasma creatinine was the same as in control animals

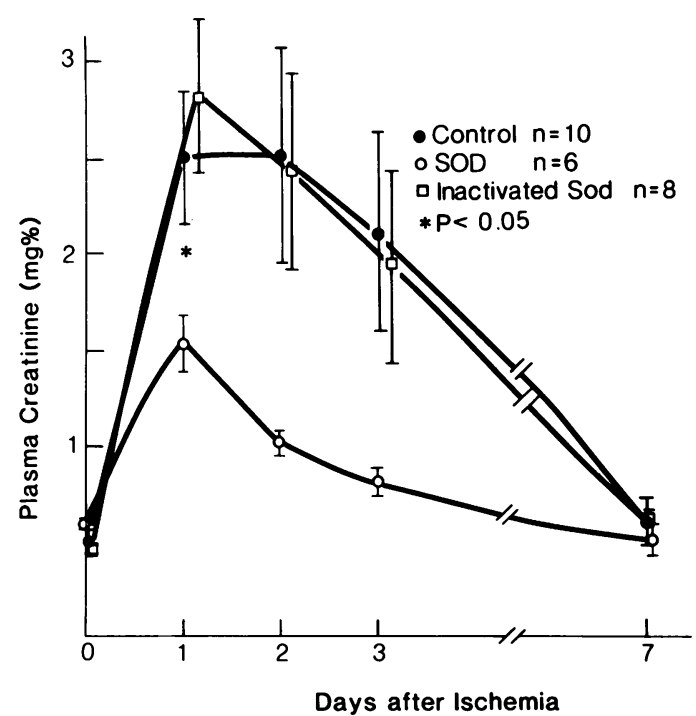

Figure 1. The effect of SOD on renal function after renal ischemia. $\mathrm{mg} \%, \mathrm{mg} / \mathrm{dl}$. 


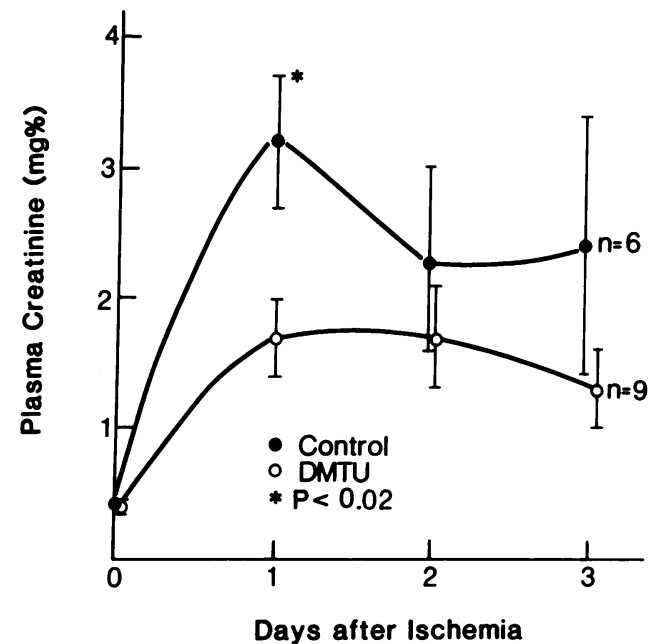

Figure 2. The effect of DMTU on renal function after renal ischemia. $\mathbf{m g} \%, \mathrm{mg} / \mathrm{dl}$.

throughout the $7 \mathrm{~d}$ of observation. Inulin clearance $24 \mathrm{~h}$ after renal ischemia was $185 \pm 57 \mu \mathrm{l} / \mathrm{min}$ in control rats and $399 \pm 82$ $\mu \mathrm{l} / \mathrm{min}$ in SOD protected rats $(P<0.05)$. RBF was also protected in SOD treated rats. RBF was $5.1 \pm 0.4 \mathrm{ml} / \mathrm{min}$ in SOD treated animals and $3.7 \pm 0.4 \mathrm{ml} / \mathrm{min}$ in control animals $(P$ $<0.05$ ) after $15 \mathrm{~min}$ of reflow.

The chemically dissimilar hydroxyl radical scavenger DMTU also provided significant protection against renal ischemia. Shown in Fig. 2 is the effect of DMTU on renal function after ischemia. Plasma creatinine in animals treated with DMTU rose to only $1.7 \pm 0.3 \mathrm{mg} / \mathrm{dl}$ on day 1 compared with $3.2 \pm 0.5 \mathrm{mg} / \mathrm{dl}$ in controls $(P<0.02)$ and was lower, although not statistically significant, on days 2 and 3 . The U/P creatinine ratio was significantly higher in animals given DMTU on day $1(P<0.05)$ (Table I), and the ratio of $U_{\mathrm{Na}}$ to $U / P$ creatinine was also lower, although not statistically, in animals treated with DMTU (Table I). Preteatment with DMTU did not alter $\mathrm{V}, \mathrm{U}_{\mathrm{Cr}}$, or $\mathrm{U}_{\mathrm{Na}} \mathrm{V}$.

Administration of the hydrogen peroxide scavenger catalase before and during ischemia did not protect against functional impairment. Plasma creatinine was $3.1 \pm 0.5,2.8 \pm 0.6$, and $2 \pm 0.4 \mathrm{mg} / \mathrm{dl}$ in catalase treated rats and $3.1 \pm 0.3,3.2 \pm 0.6$, and $2.5 \pm 0.5 \mathrm{mg} / \mathrm{dl}$ in control rats 1,2 , and $3 \mathrm{~d}$ after ischemia (not significant).

The xanthine oxidase inhibitor also provided significant protection against functional impairment when given before renal ischemia. Fig. 3 shows that plasma creatinine was $2.7 \pm 0.3$ vs. $3.6 \pm 0.2 \mathrm{mg} / \mathrm{dl}$ on day $1(P<0.05)$ and $2.2 \pm 0.6$ vs. $3.5 \pm 0.4 \mathrm{mg} / \mathrm{dl}$ on day $2(P<0.05)$ after ischemia.

Table II shows the effects of SOD and DMTU on systemic and renal hemodynamics in normal animals. No change in mean arterial pressure, cardiac output, or renal blood flow occurred after the administration of these drugs. The protective effect of SOD and DMTU in renal ischemia could not be attributed to an effect of these drugs that produces renal vasodilatation. Table III shows the effects of SOD and DMTU on urine flow rate, $U_{\mathrm{Na}}$ excretion, and urinary solute excretion. No significant changes were seen in these parameters, which also might have had an effect on the renal response to ischemia.

Morphologic studies. Blind review of specimens from vehicle and free radical scavenger treated rats revealed greater tubular injury in control kidneys. Although all kidneys showed some heterogeneous loss of brush border, bleb formation, cytoplasmic vacuolization, cellular necrosis, and tubular luminal debris and obstruction, damage was less marked in SOD treated kidneys. The mean histologic score for the SOD treated kidneys was $448 \pm 15$, whereas that for the control kidneys was $556 \pm 19(P<0.01)$. Control kidneys differed from SOD treated kidneys, in most part, because of a greater extent of cellular necrosis and tubular obstruction. There was no difference between control and SOD treated kidneys with regard to the pattern or distribution of lesions.

Lipid peroxidation by oxygen free radicals. Ischemia plus reflow resulted in an increase in whole kidney MDA content (Table IV). Although ischemia for $60 \mathrm{~min}$ without reestablishment of blood flow did not result in a significant increase in whole kidney MDA $(130 \pm 18$ vs. $166 \pm 17 \mathrm{nmol} / \mathrm{g}$ kidney weight; not significant), kidney MDA increased to $251 \pm 22$ $\mathrm{nmol} / \mathrm{g}$ after $15 \mathrm{~min}$ of reflow $(P<0.001)$.

MDA content was also increased in renal cortical homog-

Table I. Effect of DMTU on $U_{N a}, U / P_{C r}$, and Renal Failure Index After Ischemia

\begin{tabular}{|c|c|c|c|c|c|c|c|c|c|c|c|c|}
\hline \multirow[b]{2}{*}{ Day } & \multicolumn{4}{|c|}{$\mathrm{U}_{N_{0}}$ (meq/liter) } & \multicolumn{4}{|l|}{$\mathrm{U} / \mathbf{P}_{\mathrm{Cr}}$} & \multicolumn{4}{|c|}{ Renal failure index } \\
\hline & 0 & 1 & 2 & 3 & 0 & 1 & 2 & 3 & 0 & 1 & 2 & 3 \\
\hline $\begin{array}{l}\text { Control } \\
\qquad(n=6)\end{array}$ & $119 \pm 16$ & $38 \pm 7$ & $55 \pm 11$ & $35 \pm 10$ & $257 \pm 51$ & $12 \pm 3$ & $21 \pm 6$ & $19 \pm 9$ & $0.5 \pm 0.08$ & $5.6 \pm 2.4$ & $3.8 \pm 1$ & $3.5 \pm 1.5$ \\
\hline $\begin{array}{l}\text { DMTU } \\
(n=9) \\
P \text { value }\end{array}$ & $\begin{array}{l}138 \pm 12 \\
\text { NS }\end{array}$ & $\begin{array}{l}47 \pm 7 \\
\text { NS }\end{array}$ & $\begin{array}{l}35 \pm 7 \\
\text { NS }\end{array}$ & $\begin{array}{l}62 \pm 18 \\
\text { NS }\end{array}$ & $\begin{array}{l}313 \pm 52 \\
\text { NS }\end{array}$ & $\begin{array}{l}35 \pm 8 \\
0.05\end{array}$ & $\begin{array}{l}46 \pm 10 \\
\text { NS }\end{array}$ & $\begin{array}{l}48 \pm 11 \\
\text { NS }\end{array}$ & $\begin{array}{l}0.5 \pm 0.08 \\
\text { NS }\end{array}$ & $\begin{array}{l}2.6 \pm 1 \\
\text { NS }\end{array}$ & $\begin{array}{l}2.1 \pm 1.3 \\
\text { NS }\end{array}$ & $\begin{array}{l}1.4 \pm 0.5 \\
\text { NS }\end{array}$ \\
\hline
\end{tabular}

Renal failure index $=U_{\mathrm{Na}} \div \mathrm{U} / \mathrm{P}_{\mathrm{Cr}}$. NS, no significant difference. 


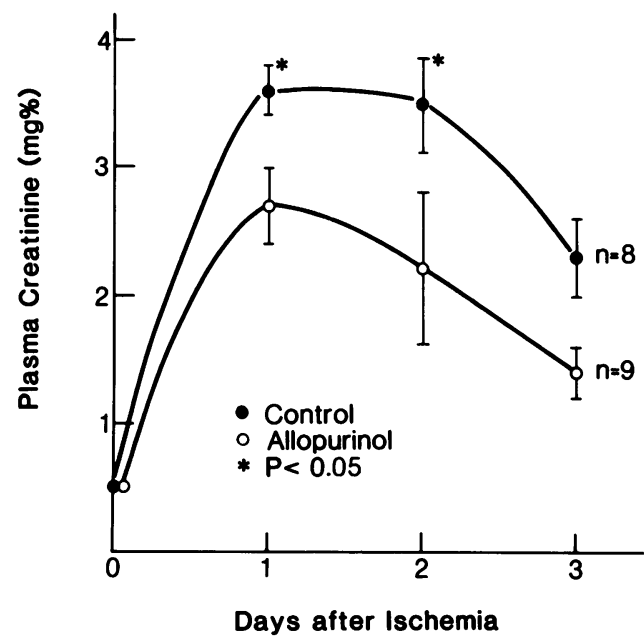

Figure 3. The effect of allopurinol on renal function after renal ischemia. $\mathrm{mg} \%, \mathrm{mg} / \mathrm{dl}$.

enates after ischemia plus reflow, as shown in Table $V$. Although we could not detect an effect of SOD pretreatment on the increase in renal cortical lipid peroxidation after ischemia plus reflow, after SOD treatment we did find a decrease in lipid peroxidation in mitochondria isolated from the renal cortex (Table VI). Mitochondria from the nonischemic renal cortex contained $5.4 \pm 1.5 \mathrm{nmol} \mathrm{MDA} / \mathrm{mg}$ protein, whereas mitochondria from kidneys made ischemic and reperfused for $15 \mathrm{~min}$ contained $7.0 \pm 1.1 \mathrm{nmol} \mathrm{MDA} / \mathrm{mg}$ protein $(P<0.05)$. SOD treatment blocked the increase in lipid peroxidation since cortical mitochondria from these rats contained only $5.6 \pm 0.8$ nmol MDA $/ \mathrm{mg}$ protein $(P<0.05$ vs. ischemic control), a value no different from nonischemic levels. Assays of cortical homogenate MDA had greater intraassay variation than did assays of mitochondrial MDA, although interassay variation was large in both. This difference might be due to the more

Table II. Effects of SOD and DMTU on Systemic and Renal Hemodynamics in Normal Animals

\begin{tabular}{llll}
\hline & MAP & $\begin{array}{l}\text { Cardiac } \\
\text { index }\end{array}$ & $\begin{array}{l}\text { Renal } \\
\text { blood } \\
\text { flow }\end{array}$ \\
\hline & $m m H g$ & $\begin{array}{l}\mathrm{m} / \mathrm{min} \\
\text { per } \mathrm{kg}\end{array}$ & $\begin{array}{l}\mathrm{ml} / \mathrm{min} \\
\mathrm{per} \mathrm{g}\end{array}$ \\
Control $(n=8)$ & $115 \pm 2.4$ & $283 \pm 16$ & $5.6 \pm 0.6$ \\
SOD $(n=6)$ & $115 \pm 3.7$ & $256 \pm 12$ & $6.7 \pm 0.7$ \\
DMTU $(n=6)$ & $118 \pm 3.5$ & $293 \pm 9$ & $5.7 \pm 0.3$ \\
Control vs. SOD & NS & NS & NS \\
Control vs. DMTU & NS & NS & NS \\
\hline
\end{tabular}

MAP, mean arterial pressure; NS, no significant difference. heterogeneous nature of cortical tissue than of the mitochondrial fraction. We believe that these technical considerations might explain our inability to detect a difference in MDA in cortical homogenates after SOD, and that the mitochondrial data are more likely to be representative.

\section{Discussion}

These studies demonstrate that the inhibition of oxygen free radical generation and the administration of two very different free radical scavengers provide protection against renal functional impairment after renal ischemia. Plasma creatinine was $\sim 50 \%$ lower in animals treated with SOD before renal artery occlusion, and inulin clearance $24 \mathrm{~h}$ after ischemia was twice as high in rats who had received SOD than in animals with renal ischemia not given SOD. Similarly, DMTU, a scavenger of hydroxyl radical, also provided protection of renal function after renal ischemia. Tubular function evaluated by tubular reabsorption of water, estimated by the U/P creatinine ratio, was also better preserved in rats given DMTU before ischemia. Furthermore, allopurinol, which is not a free radical scavenger but which acts by preventing oxygen free radical generation, also protected renal function after ischemia to a similar degree. Together these findings support a role for oxygen free radicals in producing renal functional impairment after ischemia.

Oxygen free radical-mediated damage after ischemia has been studied in myocardium, brain, and small intestine (811). A possible role for oxygen free radical damage after ischemia of the kidney has not previously been studied. There is multiple evidence to suggest such a role of oxygen free radicals in renal ischemia. Renal tissue contains the enzyme xanthine oxidase (20), and during renal ischemia tissue levels of the substrate for xanthine oxidase, hypoxanthine, rise rapidly to levels 10 to 300 times greater than normal $(3,4)$. Although we did not directly measure tissue levels of endogenous scavengers, such as SOD, ascorbate, or catalase, in other organs these natural scavengers are consumed during ischemia (8, 10). However, in the present study three separate maneuvers to decrease tissue levels of oxygen free radicals protected the kidney against ischemia.

The protective effect of SOD on renal function was directly related to its ability to scavenge $\mathrm{O}_{2}^{-}$by enzymatic dismutation. When SOD, a copper-zinc metalloenzyme, was inactivated in vitro by the copper chelator diethyldithiocarbamate, protection of renal function was no longer observed. Other agents that are effective in reducing ischemic renal dysfunction, such as mannitol and furosemide, increase renal blood flow, solute excretion, or both (21-25). Neither SOD nor DMTU increased renal blood flow, urine flow rate, or solute excretion in nonischemic kidneys, although SOD did increase renal blood flow in ischemic kidneys. Both mannitol and furosemide are protective in ischemic renal failure (21-25), but Hanley and Davidson found mannitol to be the more effective agent (25). Although mannitol may cause a greater solute diuresis in the early proximal tubule than does furosemide, the present studies 
Table III. Effect of SOD and DMTU on Urine and Solute Excretion in Normal Animals

\begin{tabular}{|c|c|c|c|c|c|c|}
\hline & \multicolumn{3}{|l|}{ Control } & \multicolumn{3}{|l|}{ Drug } \\
\hline & $\mathbf{v}$ & $U_{\mathrm{Na}_{0}} \mathrm{~V}$ & $U_{\text {ond }} V$ & $\mathbf{v}$ & $\mathrm{U}_{\mathrm{N}_{0} \mathrm{~V}}$ & $\mathrm{U}_{\text {om }} \mathrm{V}$ \\
\hline & $\mu l / \min$ & $\mu e q / \min$ & mosm/min & $\mu l / m i n$ & Meq/min & Mosm/min \\
\hline SOD $(n=5)$ & $2.3 \pm 0.3$ & $0.14 \pm 0.06$ & $3.6 \pm 0.7$ & $2.7 \pm 0.3^{*}$ & $0.09 \pm 0.04^{*}$ & $4.2 \pm 1.2^{*}$ \\
\hline DMTU $(n=5)$ & $2.3 \pm 0.3$ & $0.08 \pm 0.02$ & $4.0 \pm 0.8$ & $3.3 \pm 0.2^{*}$ & $0.10 \pm 0.03^{*}$ & $4.8 \pm 0.4^{*}$ \\
\hline
\end{tabular}

osm, osmoles. * Drug period vs. control period, no significant difference.

provide an alternative explanation for its greater efficacy. Mannitol is known to be an effective hydroxyl radical scavenger (7), and a part of its protective effect in ischemic renal injury may be secondary to its ability to reduce tissue free radical levels.

Oxygen free radicals are believed to produce cellular injury by attacking membranes through peroxidation of polyunsaturated fatty acids $(6,7)$. This lipid peroxidation results in increased membrane permeability in cells, mitochondria, and lysosomes. Peroxidative injury of erythrocyte membranes has been reported to increase passive $\mathrm{K}+$ permeability with a loss of intracellular $K+(26)$. Similarly, oxygen free radical damage to endothelial cell membranes causes increased capillary permeability in hyperoxic lung injury (27) and in ischemic intestinal injury (11). Increased permeability of renal tubular cell membranes could lead to a loss of transport functions, whereas increased permeability of mitochondrial membranes would impair oxidative phosphorylation. Increased lysosomal permeability could result in the leak of hydrolytic enzymes and accelerated cellular degradation. We found that ischemia plus reflow resulted in the increased production of the lipid peroxide MDA in homogenates of whole kidney and renal cortex as well as in renal cortical mitochondria. In contrast, ischemia without reflow did not result in significant lipid peroxidation. This is not surprising since the production of superoxide radical by xanthine oxidase requires the presence of molecular oxygen. Previous observations that reperfusion

Table IV. Lipid Peroxidation After Renal Ischemia and Reflow

\begin{tabular}{ll}
\hline & MDA \\
\hline & $n m o l / g$ \\
Control $(n=8)$ & $130 \pm 18$ \\
Ischemia, 60 min $(n=5)$ & $166 \pm 17^{*}$ \\
Ischemia plus reflow, $15 \min (n=8)$ & $215 \pm 22 \ddagger \S$
\end{tabular}

* Not significantly different from control.

$\ddagger P<0.02$ vs. ischemia.

$\S P<0.001$ vs. control. of previously ischemic myocardium (10) or kidney (28) produces much more damage than that caused by ischemia alone could be explained by this effect of reperfusion that generates oxygen free radicals with subsequent lipid peroxidation.

Although we could not detect a reduction in lipid peroxidation in renal cortex after SOD, SOD did reduce lipid peroxidation in renal cortical mitochondria. Since there is a great deal of evidence that points to mitochondrial dysfunction being of great importance in acute renal failure (29), this finding may be more relevant. Mitochondria obtained from ischemic kidneys have been found to have increased ionic permeability (30) and decreased respiratory rate and acceptor control ratio of mitochondrial respiration $(31,32)$. Peroxidation of mitochondrial membranes, by causing an increase in permeability, could result in decreased mitochondrial respiration. Free radicals might also cause mitochondrial dysfunction by altering mitochondrial membrane fluidity through damage to polyunsaturated lipids and cholesterol. Mitochondrial membrane phospholipids are characterized by a high degree of unsaturation (33), and lipid peroxidation of mitochondrial phospholipids could result in the changes in mitochondrial lipids observed after ischemia (34). Furthermore, the activity of mitochondrial proton ATPase (35), the electron transport chain (33), and adenine nucleotide translocase (36) have been shown to depend on the phospholipid environment of the mitochondrial membranes.

The generation of oxygen free radicals is one of several

Table V. Effect of SOD on Lipid Peroxidation in Renal Cortex After Ischemia

\begin{tabular}{ll}
\hline & MDA \\
\hline & $\begin{array}{l}\text { nmol/mg } \\
\text { protein }\end{array}$ \\
Nonischemic $(n=3)$ & $1.24 \pm 0.22$ \\
Ischemia plus 15 min reflow $(n=6)$ & $1.71 \pm 0.17$ \\
Ischemia plus 15 min reflow, SOD treated $(n=6)$ & $1.92 \pm 0.11^{*}$
\end{tabular}

* Not significantly different from ischemia plus 15 min reflow. 
Table VI. Effect of SOD on Lipid Peroxidation

in Renal Cortical Mitochondria After Ischemia

\begin{tabular}{ll}
\hline & MDA \\
\hline & $n m o l / m g$ protein \\
Nonischemic $(n=5)$ & $5.4 \pm 1.5$ \\
Ischemia plus 15 min reflow $(n=10)$ & $7.0 \pm 1.1^{*}$ \\
Ischemia plus 15 min reflow, SOD treated $(n=9)$ & $5.6 \pm 0.8 \ddagger$
\end{tabular}

* $P<0.05$ versus nonischemic.

$\ddagger P<0.05$ versus ischemia plus $15 \mathrm{~min}$ reflow.

possible interrelated factors that may cause cellular damage after ischemia and reflow. During ischemia, high energy phosphate supplies are depleted, and the hypoxanthine derived from degradation of ATP is substrate for superoxide radical generation by xanthine oxidase. Thus, the loss of cellular ATP and oxygen free radical production may be related phenomena. Siegel et al. have shown that the administration of ATP with magnesium chloride protects renal function after ischemia (37). The magnitude of protection was similar to that seen in the present study. Perhaps the simultaneous administration of ATP and free radical scavengers would provide more complete protection than that seen with either alone. On the other hand, the administration of adenine nucleotides could potentially be harmful if the administered ATP, like endogenous ATP, were degraded during ischemia with the production of greater amounts of hypoxanthine and, therefore, increased generation of oxygen free radicals when perfusion was reestablished.

Allopurinol has been employed in other studies to prevent an irreversible loss of purine bases from cells during ischemia. When adenine nucleotides are converted to adenosine and subsequently degraded, these nucleosides are no longer available to the cell for the resynthesis of ATP when oxygen delivery is restored (4). Allopurinol inhibits the final degradative steps for adenine nucleotides. Prior administration of allopurinol protected myocardial function after coronary artery ligation in the $\operatorname{dog}(38)$, and allopurinol or SOD protected against ischemic injury to the small intestine of the cat, at least as judged histologically (39). Allopurinol has also been used to preserve kidneys for transplantation, but the results have been inconsistent $(40,41)$. Although these studies were undertaken to increase ATP in renal tissue, tissue levels of ATP after allopurinol administration were not measured. We suggest that any beneficial effects of allopurinol might be due to inhibition of oxygen free radical generation rather than to maintenance of cellular levels of adenosine.

The present studies do not provide precise localization of the site for protection by scavengers. Oxygen free radicals could theoretically produce damage in renal arteriolar endothelial cells, glomerular mesangial cells, and renal tubular epithelial cells. The decrease in RBF that occurs in acute renal failure was improved by treatment with SOD. Similar findings have been reported by Hansson et al. (42). Although this could be interpreted to suggest that SOD prevented free radical damage to vascular endothelial (21) or mesangial cells, it is also possible that the greater RBF in SOD treated rats was a secondary effect due to renal tubular cell protection. Such an effect might be the result of altered tubuloglomerular feedback or decreased interstitial edema when ischemic renal tubular epithelial cells are protected by free radical scavengers. The increase in RBF that was seen in SOD treated animals is unlikely to be the primary factor responsible for the improved GFR in these rats since there is usually a poor correlation between RBF and GFR in ischemic acute renal failure (43).

Although free radical scavengers provided protection against renal dysfunction after ischemia, the protection was not complete. There are a number of possible explanations for this finding, the most obvious being that factors other than oxygen free radicals contribute to renal damage. However, the mechanisms used to scavenge free radicals are known to be incomplete. It is not known with certainty which free radical species, $\mathrm{O}_{2}^{-}, \mathrm{H}_{2} \mathrm{O}_{2}$, or $\mathrm{OH} \cdot$ is the major species that produces tissue injury. Although SOD was protective in our studies, the enzymatic dismutation of $\mathrm{O}_{2}^{-}$by SOD yields $\mathrm{H}_{2} \mathrm{O}_{2}$, itself a toxic species (6). Scavengers for $\mathrm{H}_{2} \mathrm{O}_{2}$ were not effective in protecting renal function after ischemia. However, catalase is a large protein with a molecular weight of $\sim 250,000$. Presumably, it would have very limited glomerular filtration and access to proximal tubular cells, especially the luminal membranes. On the basis of the morphologic and lipid peroxidation studies, the renal cortex appears to be a major site for protection by free radical scavengers. SOD, on the other hand, has a molecular weight of 32,600 and is rapidly taken up by the kidney, where it has been localized to the cortex $(44,45)$. Although the extent to which SOD can enter cells and the intracellular distribution of SOD are not known, SOD provided protection based on functional as well as morphologic criteria. Likewise, DMTU can scavenge $\mathrm{OH}$ - but would not affect tissue levels of $\mathrm{O}_{2}^{-}$or $\mathrm{H}_{2} \mathrm{O}_{2}$ that could cause tissue damage. Further studies will be required to determine whether combinations of free radical scavengers or different delivery systems for these scavengers will improve the amount of protection they provide. When it becomes possible actually to measure tissue levels of these free radical species, further refinement of the choice of scavenger will enhance protection against free radical damage. Although the therapeutic importance of free radical scavengers in acute renal failure is not known, the present studies provide evidence for a role of oxygen free radicals in producing renal dysfunction after renal ischemia and reflow.

\section{Acknowledgments}

Stefan Kren provided expert technical assistance and Cindy Vipond and Anne Andersen provided secretarial assistance. 
This work was supported by National Institutes of Health grants HL17871, HL32329, and HLO1308 and by a grant from the Minnesota Medical Foundation.

\section{References}

1. Leaf, A., J. Y. Cheung, J. W. Mills, and J. V. Bonvnetre. 1983. Nature of the cellular insult in acute renal failure. In Acute Renal Failure. B. M. Brenner and J. M. Lazarus, editors. W. B. Saunders Co., Philadelphia. 2-20.

2. Hems, D. A., and J. T. Brosnan. 1970. Effects of ischemia on content of metabolites in rat liver and kidney in vivo. Biochem. $J$. 120:105-111.

3. Osswald, H., H. J. Schmitz, and R. Kemper. 1977. Tissue content of adenosine, inosine and hypoxanthine in the rat kidney after ischemia and postischemic recirculation. Pfleugers Arch. 371:45-49.

4. Miller, W. L., R. A. Thomas, R. M. Berne, and R. Rubio. 1978. Adenosine production in the ischemic kidney. Circ. Res. 43:390-397.

5. Fridovich, I. 1970. Quantitative aspects of the production of superoxide anion radical by milk xanthine oxidase. J. Biol. Chem. 245:4053-4057.

6. Fridovich, I. 1978. The biology of oxygen radicals. Science (Wash. DC). 201:875-880.

7. Kellogg, E. W., and I. Fridovich. 1975. Superoxide, hydrogen peroxide, and singlet oxygen in lipid peroxidation by a xanthine oxidase system. J. Biol. Chem. 250:8812-8817.

8. Flamm, E. S., H. B. Demopoulos, M. L. Seligman, R. G. Poser, and J. Ransohoff. 1978. Free radicals in cerebral ischemia. Stroke. 9:445-447.

9. Kogure, K., B. D. Watson, R. Busto, and K. Abe. 1982. Potentiation of lipid peroxides by ischemia in rat brain. Neurochem. Res. 7:437-454.

10. Guarnieri, C., F. Flamigini, and C. M. Caldarera. 1980. Role of oxygen in the cellular damage induced by re-oxygenation of hypoxic heart. J. Mol. Cell. Cardiol. 12:797-808.

11. Granger, D. N., G. Rutili, and J. M. McCord. 1981. Superoxide radicals in feline intestinal ischemia. Gastroenterology. 81:22-29.

12. Demopoulos, H. B., E. S. Flamm, D. D. Pietronigro, and M. L. Seligman. 1980. The free radical pathology and the microcirculation in the major central nervous system disorders. Acta Physiol. Scand. Suppl. 492:91-119.

13. Heikkila, R. E., and G. Cohen. 1977. The inactivation of copper-zinc superoxide dismutase by diethyldithiocarbamate. In Superoxide and Superoxide Dismutases. A. M. Michelson, J. M. McCord, and I. Fridovich, editors. Academic Press Inc., London. 367-373.

14. Salin, M. L., and J. M. McCord. 1974. Superoxide dismutases in polymorphonuclear leukocytes. J. Clin. Invest. 54:1005-1009.

15. Linas, S. L., and D. Dickmann. 1982. Mechanism of the decreased renal blood flow in the potassium-depleted conscious rat. Kidney Int. 21:757-764.

16. Dorfman, L. M., and G. E. Adams. 1973. Reactivity of the hydroxyl radical in aqueous solution. National Standard Reference Data System. National Bureau Standards-46. Washington DC. 72 pp.

17. Reimer, K. A., C. E. Ganote, and R. B. Jennings. 1972. Alterations in renal cortex following ischemic injury. III. Ultrastructure of proximal tubules after ischemia or autolysis. Lab. Invest. 26:347363.
18. Venkatachalam, M. A., D. B. Bernard, J. F. Donohoe, and N. G. Levinsky. 1978. Ischemic damage and repair in the rat proximal tubule: differences among the $S_{1}, S_{2}$, and $S_{3}$ segments. Kidney Int. 14:31-49.

19. Ohkawa, H., N. Ohishi, and K. Yagi. 1979. Assay for lipid peroxides in animal tissues by thiobarbituric acid reaction. Anal. Biochem. 95:351-358.

20. Battelli, M. G., E. Della Corte, and F. Stirpe. 1972. Xanthine oxidase Type $D$ (dehydrogenase) in the intestine and other organs of the rat. Biochem. J. 126:747-749.

21. Flores, J., D. R. Di Bona, C. H. Beck, and A. Leaf. 1972. The role of cell swelling in ischemic renal damage and the protective effect of hypertonic solute. J. Clin. Invest. 51:118-126.

22. Cronin, R. E., A. de Torrente, P. D. Miller, R. E. Bulger, T. J. Burke, and R. W. Schrier. 1978. Pathogenetic mechanisms in early norepinephrine-induced acute renal failure: functional and histological correlates of protection. Kidney Int. 14:115-125.

23. Patak, R. V., S. Z. Fadam, M. D. Lifschitz, and J. H. Stein 1979. Study of the factors which modify the development of norepinephrine-induced acute renal failure in the dog. Kidney Int. 15:227237.

24. DeTorrente, A., P. D. Miller, R. E. Cronin, P. E. Paulsen, A. L. Erickson, and R. W. Schrier. 1978. Effects of furosemide and acetylcholine in norepinephrine-induced acute renal failure. Am. J. Physiol. 235:F131-F136.

25. Hanley, M. J., and K. Davidson. 1981. Prior mannitol and furosemide infusion in a model of ischemic acute renal failure. Am. J. Physiol. 241:F556-F564.

26. Maridonneau, I., P. Braquet, and R. P. Garay. 1983. Na+ and $\mathrm{K}+$ transport damage induced by oxygen free radicals in human red cell membranes. J. Biol. Chem. 258:3107-3113.

27. Deneke, S. M., and B. L. Fanburg. 1980. Normobaric oxygen toxicity of the lung. N. Engl. J. Med. 303:76-86.

28. Frega, N. S., D. R. Di Bona, B. Guertler, and A. Leaf. 1976. Ischemic renal injury. Kidney Int. 10:S17-S25.

29. Humes, H. D., and J. M. Weinberg. 1983. Cellular energetics in acute renal failure. In Acute Renal Failure. B. M. Brenner and J. M. Lazarus, editors. W. B. Saunders Co., Philadelphia. 47-98.

30. Mergner, W. J., M. A. Smith, and B. F. Trump. 1977. Studies on the pathogenesis of ischemic cell injury. IV. Alteration of ionic permeability of mitochondria from ischemic rat kidney. Exp. Mol. Pathol. 26:1-12.

31. Vogt, M. T., and E. Farber. 1968. On the molecular pathology of ischemic renal cell death. Am. J. Pathol. 53:1-26.

32. Mergner, W. J., M. W. Smith, and B. F. Trump. 1977. Studies on the pathogenesis of ischemic cell injury. XI. P/O ratio and acceptor control. Virchows Archiv. B Cell Path. 26:17-26.

33. Green, D. E., and S. Fleischer. 1963. The role of lipids in mitochondrial electron transfer and oxidative phosphorylation. Biochim. Biophys. Acta. 70:554-582.

34. Smith, M. W., Y. Collan, M. W. Kaeng, and B. F. Trump. 1980. Changes in mitochondrial lipids of rat kidney during ischemia. Biochim. Biophys. Acta. 618:192-201.

35. Cunningham, C. C., and D. T. George. 1975. The relationship between bovine heart mitochondrial triphosphatase, lipophilic compounds, and oligomycin. J. Biol. Chem. 250:2036-2044.

36. Spencer, T. L., J. K. See, and F. L. Bygrave. 1976. Translocation 
and binding of adenosine nucleotides by rat liver mitochondria partially depleted of phospholipids. Biochim. Biophys. Acta. 423:365-373.

37. Siegel, N. J., W. B. Glazier, I. H. Chaudry, K. M. Gaudio, B. Lytton, A. E. Baue, and M. Kashgarian. 1980. Enhanced recovery from acute renal failure by the postischemic infusion of adenine nucleotides and magnesium chloride in rats. Kidney Int. 17:338-349.

38. DeWall, R. A., K. A. Vasko, E. L. Stanley, and P. Kezdi. 1971 Responses of the ischemic myocardium to allopurinol. Am. Heart J. 82:362-370.

39. Parks, D. A., G. B. Bulkley, D. N. Granger, S. R. Hamilton, and J. M. McCord. 1982. Ischemic injury in the cat small intestine: role of superoxide radicals. Gastroenterology. 82:9-15.

40. Toleydo-Pereyra, L. H., R. L. Simmons, and J. S. Najarian. 1974. Effect of allopurinol on the preservation of ischemic kidneys perfused with plasma or plasma substitutes. Ann. Surg. 180:780-782.

41. Toleydo-Pereyra, L. H., R. L. Simmons, L. C. Olson, and J. S.
Najarian. 1977. Clinical effect of allopurinol on preserved kidneys: a randomized double-blind study. Ann. Surg. 185:128-131.

42. Hansson, R., O. Jonsson, S. Lundstam, S. Pettersson, T. Schersten, and J. Waldenstrom. 1983. Effects of free radical scavengers on renal circulation after ischaemia in the rabbit. Clin. Sci. 65:605610.

43. Paller, M. S., and R. J. Anderson. 1983. Use of vasoactive agents in the therapy of acute renal failure. In Acute Renal Failure. B. M. Brenner and J. M. Lazarus, editors. W. B. Saunders Co., Philadelphia. 723-740.

44. McCord, J. M., and I. Fridovich. 1969. Superoxide dismutase. An enzymic function for erythrocuprein. J. Biol. Chem. 244:60496055.

45. Huber, W., and M. G. P. Saifer. 1977. Orgotein, the drug version of bovine $\mathrm{Cu}-\mathrm{Zn}$ superoxide dismutase. In Superoxide and Superoxide Dismutases. A. M. Michelson, J. M. McCord, and I. Fridovich, editors. Academic Press Inc., London. 517-536. 